\title{
Soil-moisture probe readies for launch
}

NASA mission raises hopes for improved projections of global freshwater availability.

\section{Boer Deng}

27 January 2015 I Corrected: 30 January 2015

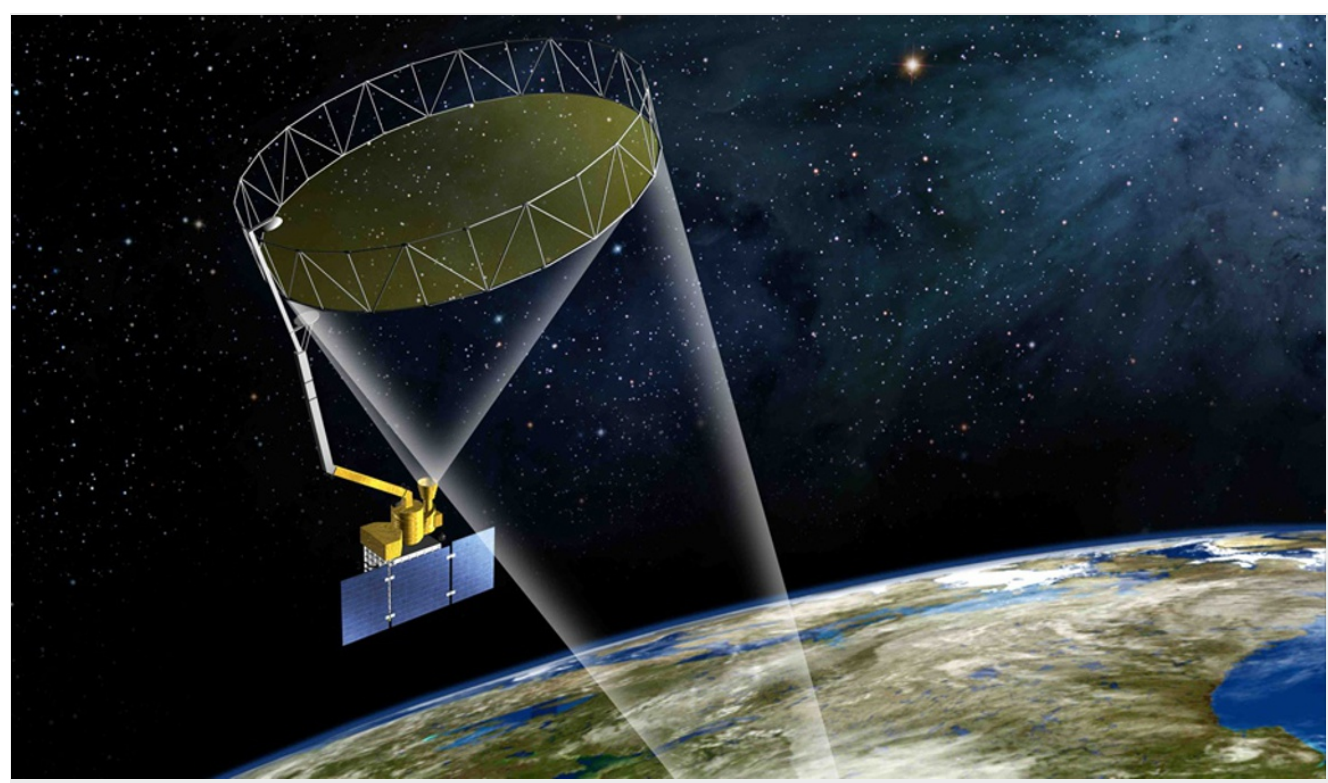

NASAJJPL

The Soil Mapping Active Passive probe is set to launch on 29 January.

New York City's fledgling water system was a casualty of the American War of Independence when the British army sabotaged the city's first reservoir. Today, New Yorkers' access to clean water faces threats of a different sort. Climate change has helped to increase the yearly variability in rainfall over the past 50 years, making the quality and availability of the city's water supply harder to predict

A new satellite from NASA, scheduled to launch on 29 January, may help to improve those predictions. The Soil Mapping Active Passive (SMAP) probe uses microwave measurements to plot moisture levels in Earth's soils. It will also show where the ground is frozen or thawed.

Both types of measurement are useful for predicting water supply, because the moisture content and temperature of soil affect how much and how quickly run-off from snow and rain drains into a reservoir. New York City now collects such data using relatively sparse ground measurements, which increases the uncertainty in its model projections of water availability. Having a fuller picture of soil conditions could be put into these forecasts to make them more accurate, says Kyle McDonald, an atmospheric scientist at the City University of New York.

\section{Diverse uses}

But tracking water supply is just one of many potential applications for the information that SMAP will collect. The US Army hopes to use the satellite's freeze-thaw data to guide troop movements over areas that are currently inaccessible, and scientists at the University of Bremen in Germany plan to track Arctic sea ice conditions. Insurance firms might apply soil-moisture values to models used for pricing crop insurance, and scientists with the government-funded US Drought Monitor service could use the satellite observations to improve their predictions.

"With previous projects, it has always been as if you collected the data, threw it over a wall and said to users, 'here, catch'," says Dara Entekhabi, an environmental engineer at the Massachusetts Institute of Technology in Cambridge, and the leader of the SMAP science team. "With SMAP, we are trying quite a different model, with partners who can give us feedback on what is useful and how to package our data in ways we didn't anticipate."

But first, the mission team will need to check the satellite data against ground measurements collected by networks of soil sensors, 
such as those used to monitor New York City's watersheds. Patchworks of national and regional groups run these networks, and operations vary. The densest web of stations, in Oklahoma, has only one measurement station every 30 kilometres. Unlike most places in the United States, the Oklahoma network has at least one in every county.

\section{Image boost}

This neatly illustrates the need for a satellite. Costs and logistics would make gathering the same level of data from ground sensors alone impossible. "Out here in the West, there are just acres and acres of privately owned land," says Todd Caldwell, a geologist at the University of Texas at Austin. "You run into all sorts of problems trying to convince neighbours to let you put up research sensors on their properties."

SMAP also improves on the image quality of a European Space Agency satellite launched in 2009 called Soil Moisture Ocean Salinity, or SMOS. Each SMOS radio scan sweeps across a 30- to 50-kilometre radius; SMAP scans across 9 kilometres. That creates a map with sharper resolution and more-precise measurements.

As for the impact on water management, "having the results from SMAP could be exciting", says Caldwell. "Everyone is trying to figure out how to better integrate soil moisture into their models," he explains. In Texas, for example, recent wet years have not returned reservoirs to pre-2011 levels, when the state suffered a severe drought. A clearer picture of how much rainfall is now locked away in soil will be informative for understanding reservoir replenishment after future droughts.

In New York City, better soil-moisture data in forecast models will mean a better grasp of the resilience of the water supply. That will ensure a city in which, as one nineteenth-century ode puts it, "posterity shall mingle/Like the gathered waters here".

Nature | doi:10.1038/nature.2015.16764

\section{Corrections}

Corrected:This story originally said that Todd Caldwell was based at the Texas Soil Observation Network in Fredericksburg. In fact, he is at the University of Texas at Austin. The text has now been corrected.

\section{References}

1. Entekhabi, D. et al. Proc. IEEE 98, 704-716 (2010). 